\title{
Recalling Ivory's Theorem
}

Hellmuth Stachel

Affiliation-Professor Vienna University of Technology Austria

Ivory's Theorem states that in each curvilinear quadrangle of a confocal net of conics the two diagonals have the same lengths. This theorem is valid not only in the Euclidean plane, but also in planar hyperbolic, spherical and pseudo-Euclidean (or Minkowski) geometry, and similar statements hold in all dimensions. Recent publications on this theorem and its generalizations on surfaces are the reason to focus again on this topic and to show a few algebraic consequences

Keywords: Ivory's Theorem, confocal conics, incircular net, Poncelet grid.

\section{INTRODUCTION}

Ivory's Theorem [1] states that in each curvilinear quadrangle PP'Q'Q of a confocal family of conics the two diagonals have the same lengths $d\left(P^{\prime}\right)=d\left(P^{\prime} Q\right)$ (Fig. 1). This theorem is valid not only in the Euclidean plane, but also in hyperbolic, spherical and pseudoEuclidean (or Minkowski) geometry. Similar statements are valid in all dimensions (see, e.g., [1-7]). A converse of the Euclidean version is proved in [8].
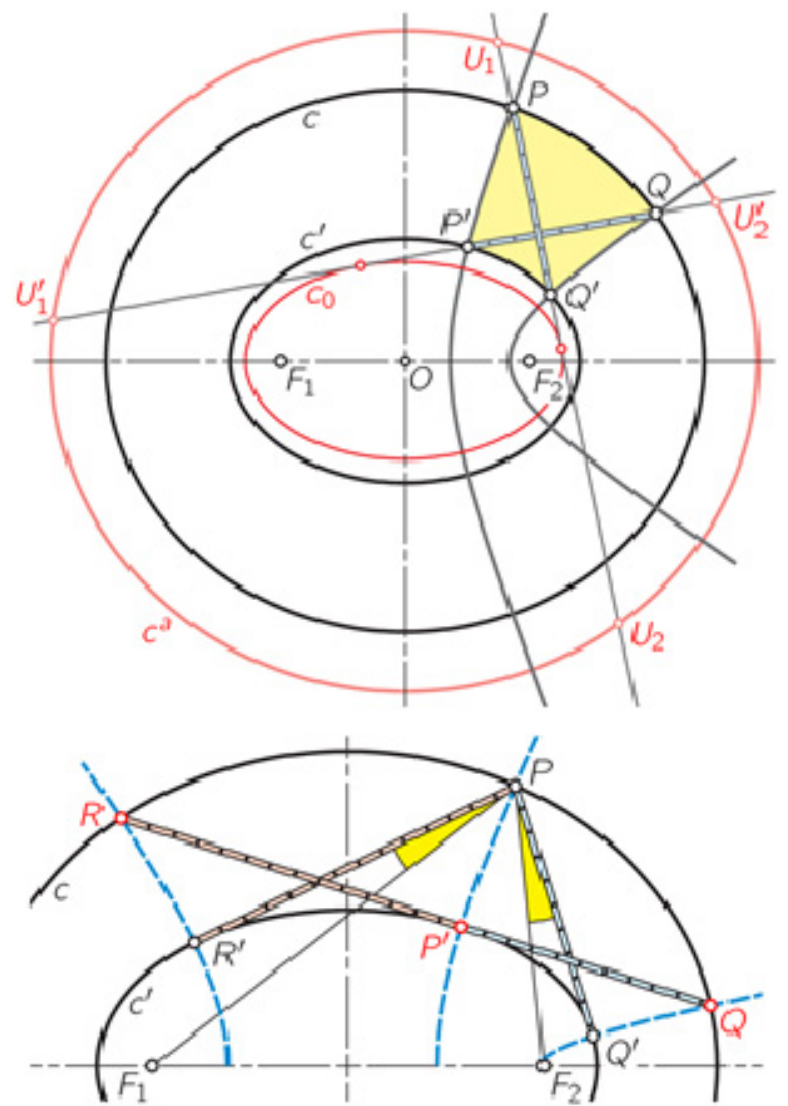

Figure 1. Ivory's Theorem in the Euclidean and hyperbolic plane, $d\left(P Q^{\prime}\right)=d\left(P^{\prime} Q\right), d\left(P R^{\prime}\right)=d\left(P^{\prime} R\right)$

Due to recent publications $[5,9]$ we focus again on this topic and show a few consequences. While [5]

Received: June 2018, Accepted: November 2018. Correspondence to: Hellmuth Stachel, AffiliationProfessor, Vienna University of Technology, Vienna, Austria

E-mail: stachel@dmg.tuwien.ac.at doi:10.5937/fmet1902355S

(C) Faculty of Mechanical Engineering, Belgrade. All rights reserved presents a differential-geometric approach, which is also valid for Liouville and Stäckel nets on surfaces, we emphasize algebraic aspects.

Two confocal central conics of the same type in the Euclidean plane can be represented as

$c:\left(1-\lambda^{2}\right) x^{2}+\left(1-\mu^{2}\right) y^{2}=C, c^{\prime}: \frac{1-\lambda^{2}}{\lambda^{2}} x^{2}+\frac{1-\mu^{2}}{\mu^{2}} y^{2}=C$

where $\lambda, \mu \quad \mathfrak{R} \backslash\{0,1\}$ and $\mathrm{C}=$ const. The affine transformation $(x, y) \rightarrow\left(x^{\prime}, y^{\prime}\right)=(\lambda x, \mu y)$ maps $\mathrm{c}$ onto $\mathrm{c}^{\prime}$. Confocal parabolas can be represented as

$c:-4 p x+\left(1-\mu^{2}\right) y^{2}=C, \quad c^{\prime}:-4 p(x-p)+\frac{1-\mu^{2}}{\mu^{2}} y^{2}=C$,

where $p \neq 0$ and $\mu \neq 0,1$. Here the affine transformation $(x, y) \rightarrow\left(x^{\prime}, y^{\prime}\right)=(x+p, \mu y)$ takes $c$ onto $c^{\prime}$. In both cases a straight forward computation shows that for any two points $P=\left(x_{1}, y_{1}\right) \quad \mathrm{c}$ and $Q^{\prime}=\left(x_{2}^{\prime}, y_{2}^{\prime}\right) \quad \mathrm{c}^{\prime}$ their distance equals that between the image $P^{\prime}=\left(x_{1}^{\prime}, y_{1}{ }^{\prime}\right)$ of $P$ and the preimage $Q=\left(x_{2}, y_{2}\right)$ of $Q^{\prime 1}$.

In the case of confocal conics with the center $O$ we can confirm similarily that

$$
\mathrm{d}(\mathrm{OP})^{2}+\mathrm{d}\left(\mathrm{OQ}^{\prime}\right)^{2}=\mathrm{d}\left(\mathrm{OP}^{\prime}\right)^{2}+\mathrm{d}(\mathrm{OQ})^{2}
$$

and for the dot product of vectors

$$
\operatorname{vec}(\mathrm{OP}) \cdot \operatorname{vec}\left(\mathrm{OQ}^{\prime}\right)=\operatorname{vec}\left(\mathrm{OP}^{\prime}\right) \cdot \operatorname{vec}(\mathrm{OQ})
$$

More general, for any coaxial conic $d$ holds: $P$ and $Q$ ' are conjugate with respect to ('w.r.t.' in brief) $d$ if and only if $P^{\prime}$ and $Q$ are conjugate w.r.t. the conic $d$. This means in the case $d=c^{\prime}:$ If $Q, R \in c$ lie on the tangent to $c^{\prime}$ at $P^{\prime}$ then $Q^{\prime}, R^{\prime} \in c^{\prime}$ are the points of contact of the tangents drawn from $P \in c$ to $c^{\prime}$ (Fig. 1, right). By the same token, these tangents have common angle bisectors with the lines connecting $P$ with the focal points (see, e.g., [10, p. 42]).

If a conic of a given confocal family serves as absolute conic $c^{\mathrm{a}}$ in the Cayley-Klein model of a hyperbolic geometry (Fig. 1, left) then the conics $c$ and $c^{\prime}$ are also confocal in the hyperbolic sense, i.e., they share the (complex conjugate) common tangents with the absolute conic $c^{\mathrm{a}}$. Therefore (e.g., according to [15]) there are equal cross ratios $\left(P Q^{\prime} U_{1} U_{2}\right)=\left(P^{\prime} Q U_{1}^{\prime} U_{2}^{\prime}\right)$ with the respectively collinear absolute points $U_{1}, \ldots$, $U_{2}$ '. In the limiting case $U_{1}=U_{2}$ we obtain a result, which is cited in $[11$, p. 153$]$, but probably has been known earlier: 
Lemma 1. In each Ivory quadrangle the two diagonal lines are tangent to the same conic $c^{\mathrm{a}}$ of the confocal family (Fig. 1, left).

\section{SOME CONSEQUENCES}

Ivory's Theorem and Lemma 1 can be used to reprove a theorem recently published.

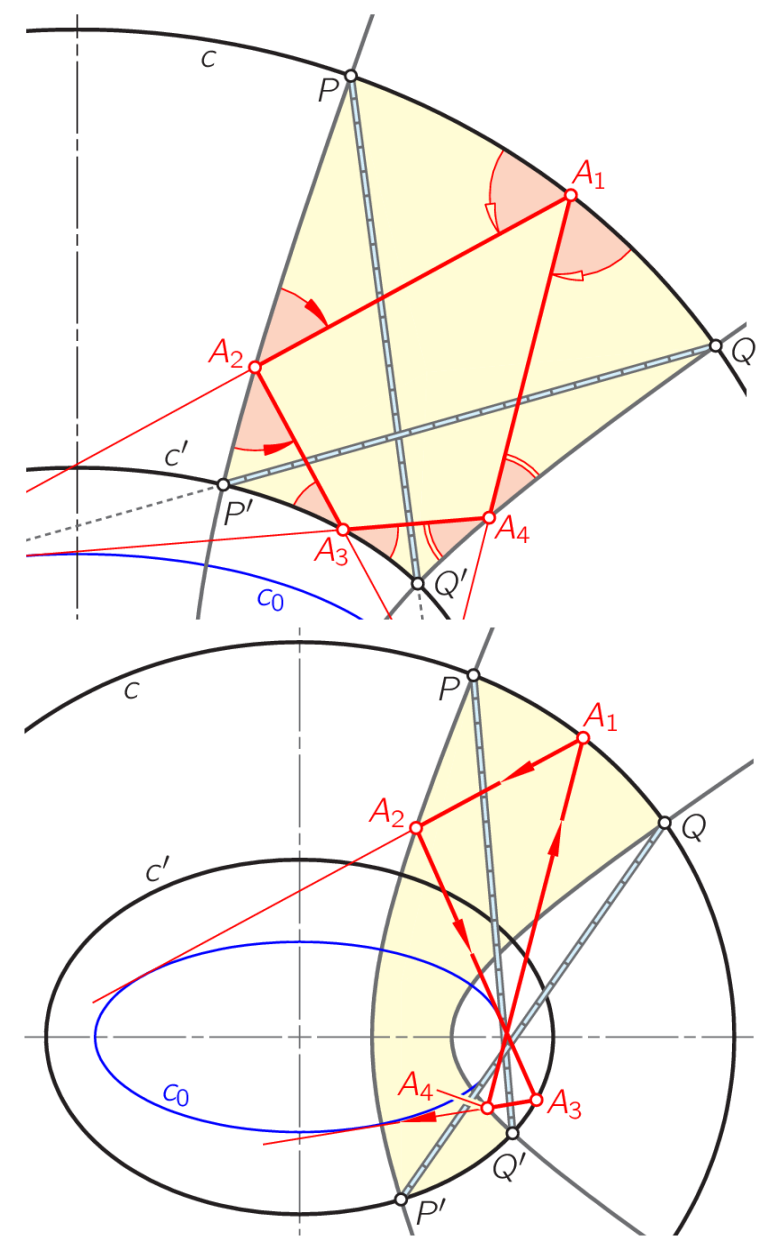

Figure 2. All billiards consisting of tangents to $c_{0}$ are closing 'within' $P P^{\prime} Q$ 'Q)

Theorem 2. (Izmestiev, Tabachnikov [5]) Given a confocal family of conics, in each Ivory quadrangle $P P^{\prime} Q^{\prime} Q$ with diagonals tangent to $c_{0}$ all billiards with sides being tangent to $c_{0}$ are closing and have equal lengths (Fig. 2).

Proof: Let $c, h_{1}, c^{\prime}, h_{2}$ be the conics carrying the curved sides of the Ivory quadrangle $P P^{\prime} Q^{\prime} Q$ (Fig. 3). We choose a point $A_{1} \in c$ within the curved side $P Q$ and denote with $h_{3}$ the second confocal conic passing through $A_{1}$. If $D_{1}$ is a point of intersection between $h_{3}$ and the diagonal $P Q^{\prime}$ then there is a sub-quadrangle $P A_{1} D_{1} A_{2}$ with $A_{2} \in \mathrm{h}_{1}$ and one diagonal tangent to $c_{0}$. Hence, by virtue of Lemma 1, also the line $A_{1} A_{2}$ contacts $c_{0}$.

The second confocal conic $c^{\prime \prime}$ through $A_{2}$ intersects $P^{\prime} Q$ at $D_{2}$, and thus we obtain a second sub-quadrangle $P^{\prime} A_{2} D_{2} A_{3}$ with diagonals tangent to $c_{0}$. Similarily we find a point $D_{3} \in P Q^{\prime}$ and furtheron $A_{4} \in h_{2}$. Finally, the quadrangle $A_{1} D_{4} A_{4} Q$ reveals that the line $A_{1} A_{4}$ is tangent to $c_{0}$, too.
We infer from Ivory's Theorem that

$$
\begin{aligned}
& d\left(A_{1} A_{2}\right)+d\left(A_{2} A_{3}\right)+d\left(A_{3} A_{4}\right)+d\left(A_{4} A_{1}\right)=d\left(P D_{1}\right)+ \\
& d\left(P^{\prime} D_{2}\right)+d\left(D_{3} Q^{\prime}\right)+d\left(D_{4} Q\right) \\
& \quad=\left(d\left(P Q^{\prime}\right)-d\left(D_{1} D_{3}\right)\right)+\left(d\left(P^{\prime} Q\right)+d\left(D_{2} D_{4}\right)\right)= \\
& 2 d\left(P Q^{\prime}\right) .
\end{aligned}
$$

On the other hand, the focal properties yield equal angles at $A_{1}, \ldots, A_{4}$, as indicated in Fig. 2, left. This confirms that $A_{1} \ldots A_{4}$ is a closing billiard within the Ivory quadrangle $P P^{\prime} Q^{\prime} Q$.

Figure 2 shows on the right hand side that for Ivory quadrangles, which cross an axis, the billiard $A_{1} \ldots A_{4}$ can look quite different. This calls to mind that the construction of the billiard for given $A_{1}$, as listed above, is ambiguous, since the point of intersection between a line and a conic is not unique. Only the respective fourth vertex of a curved Ivory quadrangle is unique because of the affine transformations mapping one side on the opposite side.

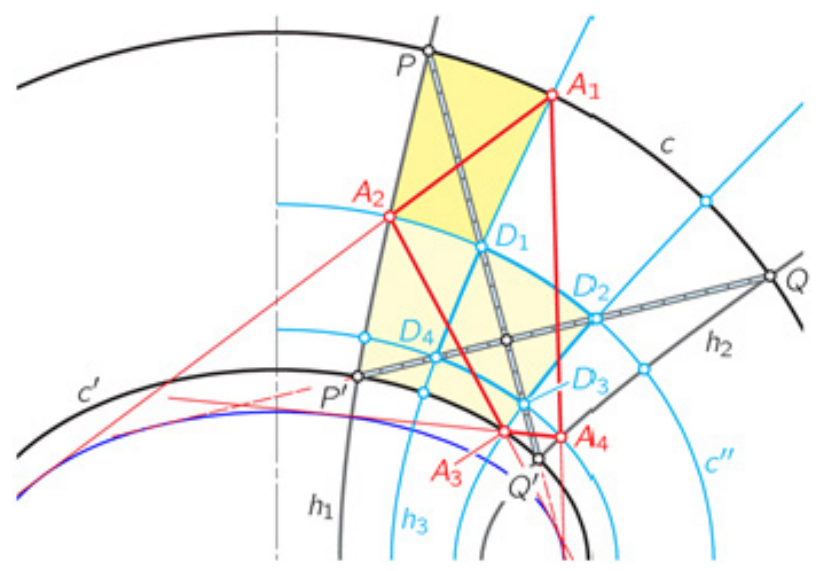

Figure 3. The sides of the billiard and the diagonals of the bounding quadrangle $P P^{\prime} Q ' Q$

In [5] the authors reprove in a differential-geometric way (note Section 3 ) the following theorem (see Fig. 4).

Theorem 3. If the tangents drawn from any two points $\mathrm{A}_{1}, \mathrm{~B}_{1}$ of a conic $\mathrm{c}_{1}$ to a confocal conic $\mathrm{c}_{0}$ form a quadrilateral then each other pair of opposite vertices (A ,B), $\mathrm{i}=2,3$, belongs to the same conic $\mathrm{c}$ of the confocal family. The quadrilateral is 'incircular', i.e., it has an incircle.

This theorem has already been published by Chasles $[12$, p. 841] and later by Böhm in [13, p. 221]. The same theorem was studied recently in [9]. A projective version of this statement is given below in Theorem 4 and proves at the same time the properties of Poncelet grids (see, e.g., [10, p. 412]).

The second part of Theorem 3, which is also discussed in [14], can be concluded from Ivory's Theorem, as shown in Fig. 4: The respectively second confocal conics through $\mathrm{A}_{1}, \mathrm{~B}_{1}, \mathrm{~A}_{2}$, and $\mathrm{B}_{2}$ define four Ivory quadrangles. The diagonals passing through the common vertex $\mathrm{S}$ must be aligned, since by Lemma 1 they are tangent to $\mathrm{c}_{0}$. Thus we can immediately figure out that in the quadrangle $\mathrm{A}_{1} \mathrm{~A}_{2} \mathrm{~B}_{1} \mathrm{~B}_{2}$ the sums of lengths of opposite sides equal $\mathrm{d}\left(\mathrm{PQ}^{\prime}\right)$.

In the sequel, the term 'conic' stands for regular conics, seen as set of their tangent lines, as well as for 
pairs of line pencils and for single line pencils with multiplicity two. Expressed in terms of homogeneous line coordinates, the corresponding quadratic forms have rank 3, 2 or 1, respectively. Moreover, we use the term range for a pencil of dual conics, i.e., a pencil in line coordinates. The term net denotes a 2-parametric linear system of dual curves of degree 2. Obviously, conics and ranges included in a net can be seen as points and lines of a projective plane. Any two ranges in a net must have a conic in common (compare with [15, Théorèmes I - IV]).

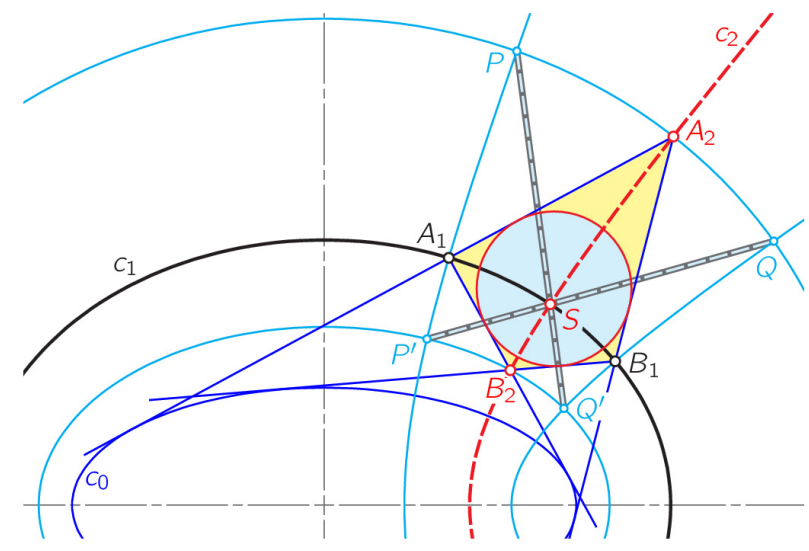

Figure 4. An incircular quadrangle $A_{1} A_{2} B_{1} B_{2}$ of tangents (Theorem 3)

Theorem 4. Let $c_{0}$ be any conic and $A_{1}, B_{1}$ two points such that the tangents $t_{1}, \ldots, t_{4}$ drawn from $A_{1}$ and $B_{1}$ to $c_{0}$ form a quadrilateral. Its remaining pairs of opposite vertices are denoted by $\left(A_{i}, B_{i}\right)$ for $i=2,3$ (Fig. 5).

(i) For any conic $c_{1}$ passing through $A_{1}$ and $B_{1}$ there exist conics $c_{i}$ through $A_{i}$ and $B_{i}$ such that $c_{i}$ belongs to the range $R_{c}$ spanned by $c_{0}$ and $c_{1}$.

(ii) If $R_{c}$ includes pairs of line pencils with carriers $\left(E_{j}\right.$, $\left.F_{j}\right), j=1, \ldots$, then there exist conics $d_{j}$ tangent to $t_{1}, \ldots, t_{4}$ and passing through $E_{j}$ and $F_{j}$.

(iii) The tangents at $A_{i}$ and $B_{i}$ to $c_{i}$ for $i=1,2,3$, as well as the tangents at $E_{j}$ and $F_{j}$ to $d_{j}$ for $j=1, \ldots$ meet at a common point $T$.

(iv) This result holds also true in the limiting case $t_{1}=$ $t_{2}$, where the chord $A_{2} B_{1}$ of $c_{1}$ contacts $c_{0}$ at $B_{2}$ and coincides with two of the four tangents $t_{1}, \ldots, t_{4}$. Then all conics $d_{j}$ touch $c_{0}$ at $B_{2}$ and are tangent to $t_{3}$ and $t_{4}$.

Figure 5 illustrates Theorem 4 in the particular case where $c_{0}$ and $c_{1}$ span a confocal range $\mathrm{R}_{\mathrm{c}}$. Then the real focal points and the absolute circle points serve as pairs of points $\left(E_{\mathrm{j}}, F_{\mathrm{j}}\right)$, as mentioned in (ii) and (iii). The latter correspond to the incircle $d_{2}$ of the quadrilateral $t_{1}, \ldots, t_{4}$. This circle has the center $T$.

Proof. The conics being tangent to $t_{1}, \ldots, t_{4}$ define a range $\mathrm{R}_{\mathrm{i}}$, which includes for $i=1,2,3$ the pairs of line pencils $\left(A_{\mathrm{i}}, B_{\mathrm{i}}\right)$ as well as the initial conic $c_{0}$. On the other hand, $c_{0}$ and $c_{1}$ span a range $\mathrm{R}_{\mathrm{c}}$, which contains the pairs of line pencils $\left(E_{\mathrm{j}}, F_{\mathrm{j}}\right)$. Since both ranges share the conic $c_{0}$, they span a net $\mathrm{N}$ of conics.

The pair $\left(A_{1}, B_{1}\right)$ of line pencils spans together with $c_{1}$ the range of conics sharing the points $A_{1}, B_{1}$ and the tangents there, which meet at point $T$. This range, which also belongs to $\mathrm{N}$, contains the rank-1-conic with carrier
$T$. Now each pair of line pencils $\left(A_{\mathrm{i}}, B_{\mathrm{i}}\right), \mathrm{i}=2,3$, spans with the pencil $T$ again a range within $\mathrm{N}$. This range shares with the range $\mathrm{R}_{\mathrm{c}}$ a conic $c_{\mathrm{i}}$ passing through $A_{\mathrm{i}}$ and $B_{\mathrm{i}}$ with respective tangent lines through $T$. A similar argument holds for the pair of line pencils $\left(E_{j}, F_{j}\right)$ which proves the existence of a conic $a_{j}$ through $E_{j}$ and $F_{j}$ with tangent lines passing through $T$, which also belongs to the range $R_{c}$.

All these conclusions remain valid in the case (iv), when $\mathrm{R}_{t}$ consists of conics which touch $c_{0}$ at $B_{2}$ and are tangent to $t_{3}$ and $t_{4}$.

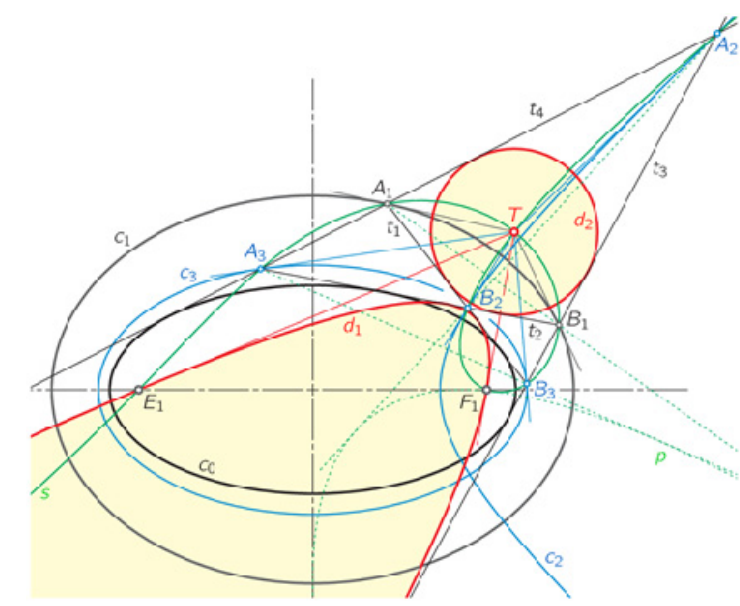

Figure 5. An incircular quadrangle $A_{1} A_{2} B_{1} B_{2}$ of tangents (Theorem 3)

Remarks. 1) With each net of conics two particular algebraic curves are associated (see [3, Sect. 77]). One is the Hessian curve of degree three. It is the envelope of all lines 1 with an undeterminate pole w.r.t. a (singular) conic included in the net. This means that line 1 either connects the carriers of the two line pencils of a rank-2-conic or it passes through the carrier of a rank-1conic. On the other hand, the locus of the carriers of included line pencils is called Cayley's curve of the net. In general it has degree six.

2) In the particular case depicted in Fig. 5 the Hessian consists of the line pencil $\mathrm{T}$ and of Chasles's parabola $\mathrm{p}$ of $\mathrm{T}$ w.r.t. the confocal range R . Cayley's curve contains the strophoid s comprising the points of contact for all tangents drawn from $\mathrm{T}$ to any conic in $\mathrm{R}$ (compare with [10, p. 342, Fig. 7.60]).

3) Nets of conics, which include a rank-1-conic, are characterized by a reducible Hessian curve. If only one rank-1-conic is included the Hessian splits into a regular conic and this singular line pencil.

In the particular case of Theorem 4 depicted in Fig. 5 with confocal $\mathrm{c}_{0}, \mathrm{c}_{1}$ the absolute points of the Euclidean plane determine one pair $\left(\mathrm{E}_{2}, \mathrm{~F}_{2}\right)$ of line pencils included in the range $\mathrm{R} \quad \mathrm{N}$. An analogous example works in the projective models of the elliptic or hyper-bolic plane. Then instead of the absolute points $\left(E_{2}, F_{2}\right)$ the absolute conic $\mathrm{c}$ is included in $\mathrm{R}$. We note that $\mathrm{c}$ spans together with the pencil $\mathrm{T}$ a range of twice touching conics. Hence, $\mathrm{d}_{2}$ is a conic which contacts $\mathrm{c}$ at two points with tangents passing through $T$. This characterizes $d_{2}$ as a non-Euclidean circle with center T. In the hyperbolic case the points of contact with $\mathrm{c}$ can be real, complex conjugate or coinciding. Accordingly, the circle $\mathrm{d}_{2}$ has either a center, or it is a hyper- or horocircle. 
Figure 6 shows the spherical model of elliptic geometry and a spherical Poncelet grid starting with a closed billiard in $\mathrm{c}_{1}$ with 9 edges tangent to $\mathrm{c}_{0}$ (note [16]). The extended sides of the billiard form a grid of nine great circles. Any two pairs of adjacent great circles form a spherical quadrangle with an incircle, which gives the depicted incircular net $[1,5]$. Similarily to the Euclidean case (Fig. 4), the existence of an incircle could also be concluded from equal sums of opposite side lengths.

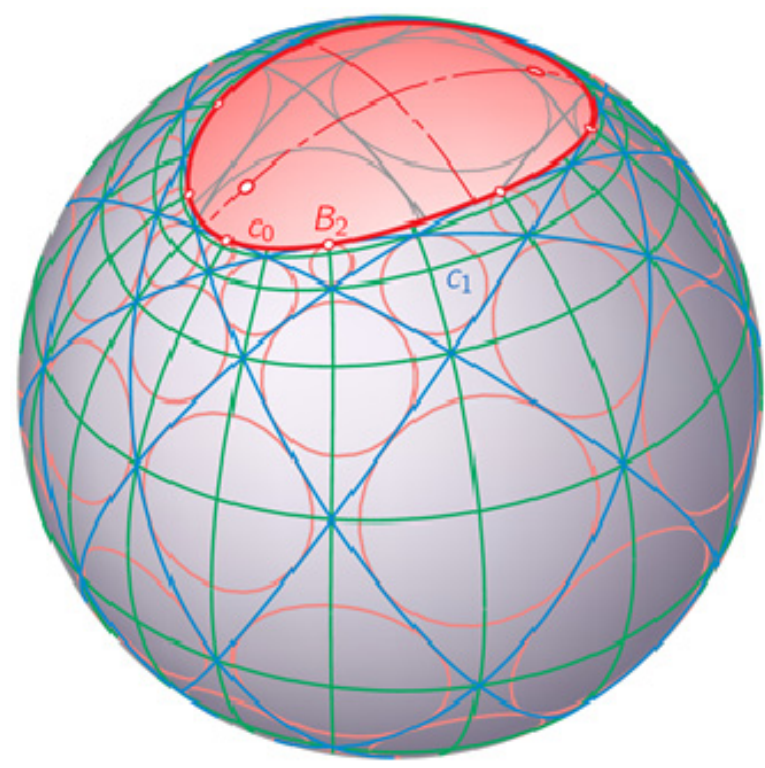

Figure 6 An incircular net of great circles tangent to $c_{0}$ on the sphere

Among the circles depicted in Fig. 6 there are also circles according to the limiting case $\mathrm{B}_{2} \quad \mathrm{c}_{0}$, as mentioned in Theorem 4, (iv). Point $\mathrm{B}_{2}$ of contact belongs together with the opposite point $\mathrm{A}_{2}$ to the second confocal conic passing through $\mathrm{B}_{2}$. We summarize this particular case of Theorem 4.

Corollary 5. Given a conic $c_{0}$ with the tangent $t$ at the point $\mathrm{B}_{2} \quad \mathrm{c}_{0}$. Let $\mathrm{t}$ intersect any confocal conic $\mathrm{c}_{1}$ at the points $A_{1}, B_{1}$, and suppose that the second tangents drawn from $A_{1}$ and $B_{1}$ to $c_{0}$ intersect at the point $A_{1}$. Then for all conics $c_{1}$ the locus of points $A_{2}$ is a confocal conic $\mathrm{c}_{2}$ passing through $\mathrm{B}_{2}$.

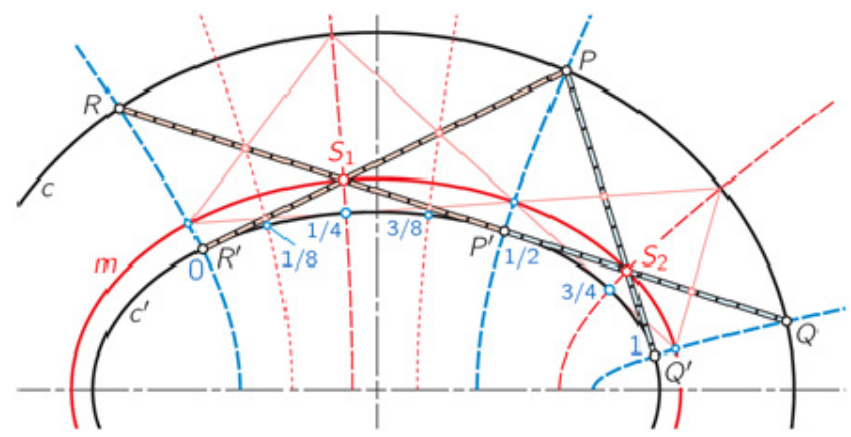

Figure 7 The crossing points $S_{1}, S_{2}$ lie on the same conic $m$

Another consequence of this subcase (iv) is illustrated in Fig. 7. Since $\mathrm{P}$ and $\mathrm{P}^{\prime}$ belong to the same conic of the family, the opposite vertices $S_{1}, S_{2}$ in the degenerated quadrangle of tangents belong to the same conic $\mathrm{m}$, too. Due to properties of Poncelet grids the conic $\mathrm{m}$ does not change while $\mathrm{P}$ varies along $\mathrm{c}$. The same can be concluded by the use of canonical coordinates, as explained in the coming section.

\section{CANONICAL COORDINATES}

The elegant differential-geometric proofs in [5] are based on the Arnold-Liouville theorem from the theory of completely integrable system. According to this, there exist cyclic canonical coordinates on $\mathrm{c}_{0}$ with the following property : If any point $\mathrm{X}$ in the exterior of $\mathrm{c}_{0}$ is parametrized by the canonical coordinates $(\mathrm{u}, \mathrm{v})$ of the tangency points of the tangent lines from $\mathrm{X}$ to $\mathrm{c}_{0}$ then the lines $\mathrm{u} \pm \mathrm{v}=$ const. are located on conics of the confocal family. In [5] $\mathrm{c}_{0}$ is an ellipse; all curves $\mathrm{u}-\mathrm{v}=$ const. are on ellipses and $\mathrm{u}+\mathrm{v}=$ const. are on hyperbolas. There is a period $p>0$ such that the parameters $\mathrm{u}$ and $\mathrm{u}+\mathrm{p}$ define the same point on $\mathrm{c}_{0}$.

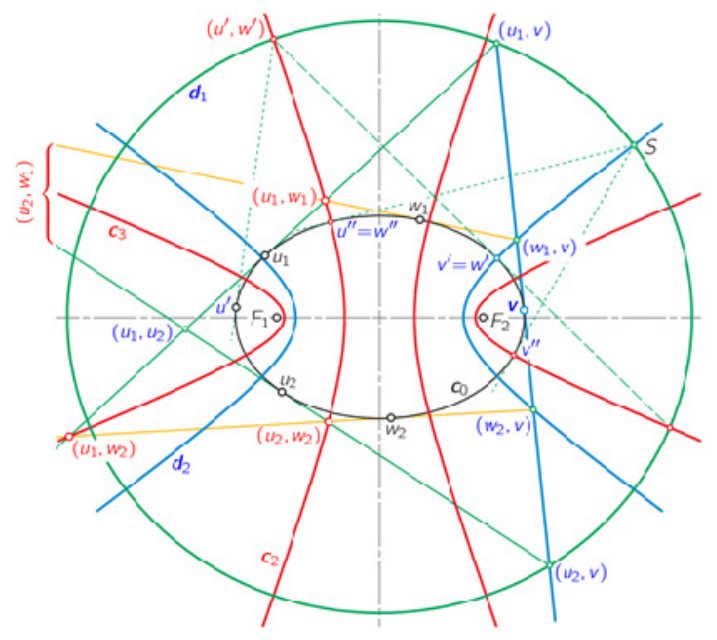

Figure 8 On the composition of the correspondances $(u, v)$ w.r.t. $d_{1}$ and $(v, w)$ w.r.t. $d_{2}$ (Theorem 6)

Algebraically, each conic $d$, confocal with $\mathrm{c}_{0}$, defines a symmetric 2-2-correspondance on $\mathrm{c}_{0}$ such that the tangents to $\mathrm{c}_{0}$ at corresponding points intersect on $\mathrm{d}$, or in other words, values $(\mathrm{u}, \mathrm{v})$ corresponding w.r.t. $d$ define an unique point of $d$.

Obviously we can compose the correspondences w.r.t. two conics confocal with $\mathrm{c}_{0}$. Suppose, $(\mathrm{u}, \mathrm{v})$ are corresponding w.r.t. the conic $\mathrm{d}_{1}$ and $(\mathrm{v}, \mathrm{w})$ w.r.t. the conic $d_{2}$. In Fig. $8 d_{1}$ is an ellipse and $d_{2}$ is a hyperbola. Then $\mathrm{u}-\mathrm{v}=\mathrm{C}_{1}$ and $\mathrm{v}+\mathrm{w}=\mathrm{C}_{2}$, and consequently $\mathrm{u}+\mathrm{w}$ $=\mathrm{C}_{1}+\mathrm{C}_{2}=$ const. The algebraic version is given below and shown in Fig. 8. The points on $\mathrm{c}_{0}$ in this figure are denoted by their parameters, while points in the exterior are labelled by pairs of parameters.

Theorem 5. Let three confocal conics $c_{0}, d_{1}, d_{2}$ be given with canonical coordinates on $\mathrm{c}_{0}$. Suppose that $(\mathrm{u}, \mathrm{v})$ are corresponding coordinates w.r.t. $\mathrm{d}_{1}$, i.e., the tangents to $c_{0}$ at the related points intersect on $d_{1}$, and $(\mathrm{v}, \mathrm{w})$ are corresponding w.r.t. $\mathrm{d}_{2}$. Then the points defined by parameters $(\mathrm{u}, \mathrm{w})$ are located on two conics $\mathrm{c}_{2}, \mathrm{c}_{3}$ of the confocal range.

Proof. Let $\mathrm{u}_{1}$ and $\mathrm{u}_{2}$ be corresponding to the coordinate $\mathrm{v}$ w.r.t. $\mathrm{d}_{1}$, and $\mathrm{w}_{1}$ and $\mathrm{w}_{2}$ be corresponding to $\mathrm{v}$ w.r.t. $d_{2}$. According to Corollary 5, for any point V c with coordinate $\mathrm{v}$ the two corresponding $\mathrm{u}$-values $\left(\mathrm{u}_{1}\right.$, $\mathrm{u}_{2}$ ) w.r.t. $\mathrm{d}_{1}$ define a point on the second confocal conic 
passing through $\mathrm{V}$, which is the same for the conic $d_{2}$. Hence, the points $A_{1}=\left(u_{1}, u_{2}\right)$ and $B_{1}=\left(w_{1}, w_{2}\right)$ satisfy the conditions of Theorem 4. Consequently, opposite vertices of the quadrilateral of tangents at $\mathrm{u}_{1}, \ldots, \mathrm{w}_{2}$ belong to the same conic $c_{1}$ (not displayed in Fig. 8). This means that the points $\left(\mathrm{u}_{1}, \mathrm{w}_{1}\right)$ and $\left(\mathrm{u}_{2}, \mathrm{w}_{2}\right)$ belong to a conic $\mathrm{c}_{2}$ and $\left(\mathrm{u}_{1}, \mathrm{w}_{2}\right)$ and $\left(\mathrm{u}_{2}, \mathrm{w}_{1}\right)$ to another conic $\mathrm{c}_{3}$.

How is this compatible with the local point of view in [5]? Why are there two conics? Globally, the parameters $(u, v)$ of points on $d_{1}$ are symmetric; this yields two values $\mathrm{u}_{1}, \mathrm{u}=$ corresponding to $\mathrm{v}$ with $\mathrm{u}_{1}-\mathrm{v}=\mathrm{C}_{1}=$ $\mathrm{v}-\mathrm{u}_{2}$. Analogously, the two $\mathrm{w}$-values for the same conic $\mathrm{d}_{2}$ satisfy $\mathrm{w}_{1}+\mathrm{v}=\mathrm{C}_{2}$ and $\mathrm{w}_{2}+\mathrm{v}=2 \mathrm{p}-\mathrm{C}_{2}$. Thus we obtain $\mathrm{u}_{1}+\mathrm{w}_{1}=\mathrm{C}_{1}+\mathrm{C}_{2}$ and $\mathrm{u}_{2}+\mathrm{w}_{2}=2 \mathrm{p}-\left(\mathrm{C}_{1}+\mathrm{C}_{2}\right)$, and on the other hand $\mathrm{u}_{2}+\mathrm{w}_{1}=\mathrm{C}_{2}-\mathrm{C}_{1}$ and $\mathrm{u}_{1}+\mathrm{w}_{2}=2 \mathrm{p}$ $-\left(\mathrm{C}_{2}-\mathrm{C}_{1}\right)$. This reveals also that these two conics remain constant while the parameter $\mathrm{v}$ varies.

\section{REFERENCES}

[1] Ivory, J. (1809). On the Attractions of homogeneous Ellipsoids. Phil. Trans. of the Royal Society of London 99, pp. 345-372.

[2] Böhm, W. (1965). Ein geometrischer Beweis des Satzes von Ivory. Arch. Math. 16, pp. 135-137.

[3] Dingeldey, F. (1903-1915). Kegelschnitte und Kegelschnittsysteme. In: Encyklopädie der math. Wiss. III.2.1, no. C1, pp. 1-160, B.G. Teubner, Leipzig.

[4] Horváth, Á.G. (2011). Projection pencils of quadrics and Ivory's theorem. J. Geom. 102, pp. 85-101.

[5] Izmestiev, I., Tabachnikov, S. (2017). Ivory's Theorem revisited. Journal of Integrable Systems 2/1

[6] Stachel, H. (2002). Ivory's Theorem in the Minkowski Plane. Math. Pannonica 13, pp. 11-22.

[7] Stachel, H., Wallner, J. (2004). Ivory's Theorem in Hyperbolic Spaces. Sib. Math. J. 45, no. 4, pp. 785 794, russ: Sib. Mat. Zh. 45, no. 4, pp. 946-959.

[8] Stachel, H. (2002). Configuration Theorems on Bipartite Frameworks. Rend. Circ. Mat. Palermo, II. Ser., 70, pp. 335-351.
[9] Akopyan A.W et al. (2017). Incircular nets and confocal conics. Trans. Amer. Math. Soc., Nov. 16, 2017 (arXiv:1602.04637v2 [math.DS] 27 Oct 2017).

[10] Glaeser, G., Stachel, H., Odehnal, B. (2016). The Universe of Conics. Springer Spectrum, Berlin Heidelberg..

[11]Böhm, W. (1955). Die Fadenkonstruktionen der Flächen zweiter Ordnung. Math. Nachr. 13, pp. 151-156.

[12] Chasles, M. (1843). Propriétés générales des arcs d'une section conique, dont la difference est rectifiable. Comptes Rendus hebdomadaires de séances de l'Académie des sciences 17, pp. 838-844

[13]Böhm, W. (1961). Ein Analogon zum Satz von Ivory. Ann. Mat. Pura Appl. (4) 54, pp. 221-225.

[14]Böhm, W. (1970). Verwandte Sätze über Kreisvierseitnetze. Arch. Math. 21, pp. 326-330.

[15] Chasles, M. (1860). Résumé d'une théorie des coniques sphériques homofocales. Comptes Rendus des séances de l'Académie des Sciences 50, pp. 623-633.

[16] Tabachnikov, S. (2005). Geometry and Billiards. American Mathematical Society, Providence/ Rhode Island

\section{СЕһАЫЕ НА АЈВОРИЈЕВУ ТЕОРЕМУ}

\section{Х. Штахел}

Ајворијева Теорема тврди да у сваком криволинијском четвороуглу конфокалног прамена коника, две дијагонале имају једнаку дужину. Ова теорема је исправна не само у Еуклидској равни, већ и у раванској хиперболичко, сферној и псеудоЕуклидској геометрији (или геометрији Минковског), а слична тврђења важе и у свим димензијама. Скорашње публикације о овој теореми и њеним генерализацијама на површима разлог су за поновно фокусирање пажње на ову тему, са освртом на неколико алгебарских последица. 